\title{
Weakness of respiratory and skeletal muscles after a short course of steroids in patients with acute lung rejection
}

\author{
S. Nava*, C. Fracchia\# ${ }^{\#}$ G. Callegari” ${ }^{\#}$ N. Ambrosino", N. Barbarito*, G. Felicetti ${ }^{+}$
}

\begin{abstract}
Weakness of respiratory and skeletal muscles after a short course of steroids in patients with acute lung rejection. S. Nava, C. Fracchia, G. Callegari, N. Ambrosino, N. Barbarito, G. Felicetti. (C) ERS Journals Ltd 2002.

ABSTRACT: There have been occasional reports of acute respiratory and skeletal muscle weakness in intensive care unit patients treated with massive doses of corticosteroids. However, in this setting the concomitant use of other drugs may have influenced the finding.

In this study the effects of 5 days of treatment with high doses of steroids in consecutive patients with acute lung rejection after transplantation were systematically evaluated. Maximal inspiratory pressure during phrenic nerve stimulation and peak torque of isokinetic contraction of the quadriceps and hamstring muscles were measured objectively.

Compared to the pretreatment condition, $\sim 45 \%$ of patients showed acute generalised muscle weakness that recovered after $\sim 2$ months.

This demonstrates muscle weakness induced by steroids within patients. Eur Respir J 2002; 20: 497-499.
\end{abstract}

Lung transplantation may be a life-saving procedure in patients affected by irreversible respiratory failure. Unfortunately, rejection of a lung allograft is a relatively common event that may profoundly influence prognosis. Rescue therapy for lung rejection is based mainly on a short course of high doses of corticosteroids (e.g. $1,000 \mathrm{mg}$ of methylprednisolone for 5 consecutive days) [1]. Most of the patients are still recovering from the surgical intervention at this stage, so respiratory and skeletal muscle weakness is likely to be present [2]. Five days of treatment with massive doses of steroids have been shown, in rats, to induce severe respiratory and limb muscle wasting with alterations in muscle contractile properties [3]. The current authors systematically examined the potential deleterious effects of acute steroid administration on respiratory and limb muscle function in patients undergoing rejection of a lung transplant.

\section{Methods}

Over a 6-yr period (1992-1998) the inotropic properties of the respiratory and limb muscles in consecutive patients developing acute rejection after a single or double lung transplant were studied. Table 1 shows the main clinical and physiological characteristics of the 13 patients enrolled. The study was approved by the local Ethics Committee and informed consent to the study was given by each patient. When acute rejection

\begin{abstract}
${ }^{\#}$ Respiratory Unit and ${ }^{+}$Ergonomics Dept, Istituto Scientifico di Montescano and Respiratory Units, Istituto Scientifico di Gussago and *Pavia, Fondazione S. Maugeri Istituto Ricovero e Cura a Carattere Scientifico, Pavia, Italy.
\end{abstract}

Correspondence: S. Nava, Respiratory Unit, Fondazione S.Maugeri, Via Ferrata 8,27100 Pavia, Italy.

Fax: 390382592075

E-mail: snava@fsm.it

Keywords: Lung rejection, phrenic nerve stimulation, respiratory muscle, skeletal muscle, weakness

Received: February 282002

Accepted after revision: March 112002 was determined, both clinically and histologically, the patients followed a protocol consisting of $12 \mathrm{mg} \cdot \mathrm{kg}^{-1}$ of methylprednisolone for 3 consecutive days and $10 \mathrm{mg} \cdot \mathrm{kg}^{-1}$ for the next 2 days. Additional immunosuppressive drugs were started after this period only in the case of steroid-resistant acute rejection.

Diaphragmatic inotropic properties were assessed using the technique of electrical stimulation of the phrenic nerves [4]. Briefly, the phrenic nerves were simultaneously stimulated with $0.1 \mathrm{~ms}$ square-wave pulses, with an intensity $>20 \%$ than the minimum required to achieve maximal stimulation. The diaphragm compound action potentials evoked from each hemidiaphragm were recorded via two pairs of surface electrodes placed over the sixth and seventh intercostal spaces. Phrenic nerve stimulations were superimposed upon voluntary contractions of the diaphragm, so that the amplitude of mouth pressure generated during the manoeuvre $(P \mathrm{mt})$ decreased progressively, indicating a progressive increase in diaphragm activation. This method provides objective information on the level of diaphragm activation and how this relates to the level of inspiratory efforts achieved by the patient.

Skeletal muscle function was assessed by the peak torque of isokinetic contraction at a test speed of $120 \mathrm{~s}^{-1}$ of the flexor (hamstring; IFX) and extensor (quadriceps; IEX) muscles of the leg, measured by an isokinetic dynamometer.

All the above mentioned measurements, together 
Table 1. - Main clinical and physiological characteristics of the patients enrolled

\begin{tabular}{|c|c|c|c|c|c|c|c|c|c|c|}
\hline $\begin{array}{l}\text { Patients } \\
\text { No. }\end{array}$ & Age yrs & Sex & BMI & Pathology & $\begin{array}{l}\text { Time from } \\
\text { transplant months }\end{array}$ & $\mathrm{pH}$ & $\begin{array}{l}\mathrm{Pa}_{2} \mathrm{CO}_{2} \\
\mathrm{mmHg}\end{array}$ & $\begin{array}{l}P \mathrm{a}, \mathrm{O}_{2} \\
\mathrm{mmHg}\end{array}$ & $\begin{array}{l}\text { FEV1 } \\
\mathrm{mL}\end{array}$ & $\begin{array}{c}\mathrm{FVC} \\
\mathrm{mL}\end{array}$ \\
\hline 1 & 19 & M & 18.73 & CVD & 6 & 7.40 & 32.9 & 66.6 & 1440 & 2260 \\
\hline 2 & 26 & M & 21.06 & SPH & 2 & 7.47 & 36.8 & 94.3 & 2450 & 2520 \\
\hline 3 & 55 & M & 24.00 & COPD & 4 & 7.40 & 45.6 & 58.7 & 900 & 2530 \\
\hline 4 & 49 & M & 34.16 & IPF & 5 & 7.45 & 32.5 & 40.7 & 2110 & 2810 \\
\hline 5 & 21 & $\mathrm{~F}$ & 18.96 & CVD & 25 & 7.46 & 29 & 69.8 & 1330 & 1560 \\
\hline 6 & 49 & M & 27.65 & COPD & 1 & 7.44 & 41.3 & 68.8 & 1600 & 3200 \\
\hline 7 & 53 & M & 30.56 & COPD & 12 & 7.41 & 37.9 & 79.3 & 1580 & 3980 \\
\hline 8 & 23 & $\mathrm{~F}$ & 21.77 & CVD & 1 & 7.47 & 36 & 70.9 & 1430 & 2100 \\
\hline 9 & 52 & M & 24.96 & COPD & 8 & 7.40 & 52.2 & 48.9 & 1820 & 2760 \\
\hline 10 & 59 & M & 22.22 & IPF & 7 & 7.45 & 34.2 & 70.4 & 3001 & 3670 \\
\hline 11 & 47 & M & 19.47 & SPH & 3 & 7.38 & 48.9 & 58.3 & 2900 & 3500 \\
\hline 12 & 61 & $\mathrm{~F}$ & 16.64 & COPD & 2 & 7.40 & 52.1 & 53.5 & 1120 & 3560 \\
\hline 13 & 25 & M & 21.13 & CVD & 2 & 7.39 & 34.9 & 63.8 & & \\
\hline Mean & 41.5 & & 23.17 & & 6.0 & 7.42 & 39.6 & 65.3 & 1800 & 2940 \\
\hline SD & 15.9 & & 5.03 & & 6.5 & 0.02 & 7.8 & 14.6 & 670 & 740 \\
\hline
\end{tabular}

BMI: body mass index; $\mathrm{Pa}_{\mathrm{a}} \mathrm{CO}_{2}$ : carbon dioxide tension in arterial blood; $\mathrm{Pa}_{\mathrm{a}} \mathrm{O}_{2}$ : oxygen tension in arterial blood; FEV1: forced expiratory volume in one second; $\mathrm{M}$ : male; $\mathrm{F}$ : female; CVD: congenital vascular disease; SPH: secondary pulmonary hypertension; COPD: chronic obstructive pulmonary disease; FVC: forced vital capacity; IPF: idiopathic pulmonary fibrosis.

with pulmonary function tests (PFT), were recorded immediately before the first bolus of methyprednisolone and $24 \mathrm{~h}$ after the last administration.

The individual relationships between the $P$ mt amplitude as a function of the voluntary inspiratory effort on which electrical stimulation was superimposed showed that in most cases (10 of 13) no twitch could be detected during maximal efforts indicating that all stimulated motor units were fully activated. The maximum pressures predicted (MIPp) from the twitch occlusion were calculated using the following equation:

$$
\mathrm{MIP}_{\mathrm{p}}=\mathrm{a}+\mathrm{b} \times \text { maximal voluntary } P_{\mathrm{mt}}
$$

where $\mathrm{a}$ and $\mathrm{b}$ are the intercept and the slope, respectively.

\section{Results}

At the time of rejection MIPp was overall markedly reduced $(43 \pm 13 \%$ of predicted). Figure 1a illustrates the individual changes in MIPp before and after the 5-day course of steroids. Six of the 13 patients showed a clear decrease $(>15 \%)$ in maximal inspiratory pressure after steroid treatment; these findings were not correlated with body mass index, age or type of surgery, but four of these six patients were affected by congenital or secondary pulmonary hypertension. Functional residual capacity, the main determinant in the assessment of the inotropic characteristic of the inspiratory muscle, was identical $(3.56 \pm 0.54$ versus $3.69 \pm 0.61 \mathrm{~L})$ before and after the treatment, as were the other PFTs. At the time of rejection IFX and IEX were also overall markedly reduced ( $53 \pm 11$ and $58 \pm 9$ of predicted, respectively). Figure $1 \mathrm{~b}$ showed that in four out of nine patients able to complete the peak torque test, IEX was decreased $>15 \%$ after the treatment. In these patients (except one) changes in MIPp closely paralleled those in IFX and IEX. Both skeletal and respiratory muscle strength fully recovered after $52 \pm 13$ days. All the patients survived the episode of rejection. The mean time of survival from enrolment into the study in the patients not showing respiratory muscle weakness was
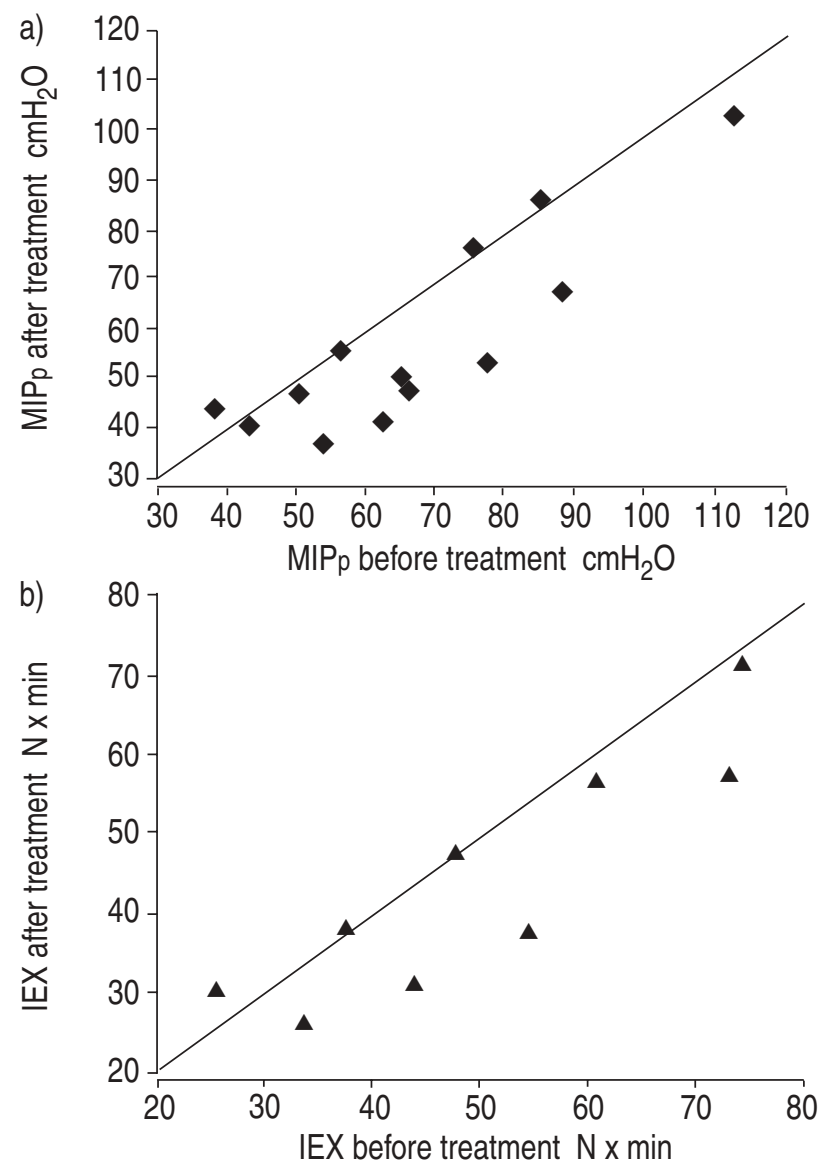

Fig. 1. - Identity plot detecting the effects of the short-term steroid administration on a) maximum inspiratory pressure predicted $(\mathrm{MIPp})$ and b) peak torque of isokinetic contraction of leg extensor (IEX). 
$63 \pm 18$ months whereas it was $45 \pm 12$ months for the remaining patients.

\section{Discussion}

There have been occasional reports of generalised weakness occurring in patients treated with massive doses of corticosteroids, sometimes interfering with the process of weaning from mechanical ventilation. However, intensive care unit patients are also likely to be treated with other drugs (antibiotics, muscle relaxants) which have been shown to produce massive neurogenic changes and rhabdomyolysis, so it is not possible to determine the significance of these findings [5]. The current authors' observations give the first systematic clinical demonstration that a high dose of steroids for only 5 days, in the absence of other therapy, induces profound respiratory and limb muscle weakness, at least in some individuals. The large majority of these patients already manifested a marked reduction in MIPp, IFX and IEX at the time of the acute rejection because they were still recovering from the surgical procedure and probably the effects of prolonged bed-rest and/or limited physical activity prior to the surgery. The occurrence of generalised muscle weakness is likely to be related to myopathy which, when it develops on a chronic basis, may also influence the survival of the patients [6], even though in most of the patients in this study full recovery was observed $\sim 2$ months after the treatment.
These data demonstrate that short-term treatment with high doses of steroids can lead to generalised muscle weakness, thus further hampering the patient's prompt clinical recovery after rejection of an allograft.

\section{References}

1. Trulock EP. Management of lung transplant rejection. Chest 1993; 103: 1566-1576.

2. Pantoia JC, Andrade FH, Stokic DS, Frost AE, Eschenbacher WL, Reid MB. Respiratory and limb muscle function in lung allograft recipients. $\mathrm{Am}$ J Respir Crit Care Med 1999; 160: 1205-1211.

3. Nava S, Gayan-Ramirez G, Rollier H, et al. Effects of acute steroid administration on ventilatory and peripheral muscles in rats. Am $J$ Respir Crit Care Med 1996; 153: 1888-1896.

4. Similowski T, Gauthier AP, Yan S, Macklem PT, Bellemare F. Assessment of diaphragm function using mouth pressure twitches in chronic obstructive pulmonary disease patients. Am Rev Respir Dis 1993; 147: 850-856.

5. Leatherman JW, Fluegel WL, David WS, Davies SF, Iber C. Muscle weakness in mechanically ventilated patients with severe asthma. Am J Respir Crit Care Med 1996; 153: 1686-1690.

6. Decramer M, de Bock V, Dom R. Functional and histologic picture of steroid-induced myopathy in chronic obstructive pulmonary disease. Am J Respir Crit Care Med 1996; 153: 1958-1964. 